\title{
CARACTERÍSTICAS MORFOGÊNICAS DO CAPIM-TANZÂNIA FERTILIZADO OU NÃO COM NITROGÊNIO NAS ESTAÇÕES DO ANO
}

\author{
MORPHOGENIC CHARACTERISTICS OF TANZANIA GRASS FERTILIZED OR NOT \\ WITH NITROGEN IN THE SEASONS OF THE YEAR
}

\author{
Bruno Shigueo IWAMOTO ${ }^{1}$; Ulysses CECATO $^{2}$; Ossival Lolato RIBEIRO ${ }^{3}$; \\ Gracielle Caroline MARI ${ }^{4}$; Edmar Pauliqui PELUSO ${ }^{4}$; Daniela Andressa Lino LOURENÇO ${ }^{5}$ \\ 1. Mestre em Pastagem e forragicultura, Programa de Pós-graduação em Zootecnia, Universidade Estadual de Maringá - UEM, PR, \\ Brasil.bshigueo@hotmail.com; 2. Professor, Doutor, Zootecnia- UEM, Maringá, PR, Brasil; 3. Professor, Doutor, Centro de Ciências \\ Agrárias, Universidade Federal da Bahia - UFBA, Salvador, BA, Brasil; 4. Mestrando(a) em Pastagem e forragicultura, Programa de \\ Pós-graduação em Zootecnia - UEM, PR, Brasil; 5. Pós-doutoranda no Department of Animal and Dairy Science University of \\ Georgia - UGA, Athens-GA, USA.
}

RESUMO: O experimento foi conduzido na Fazenda Experimental de Iguatemi - UEM, entre Abril de 2008 a Setembro de 2009, com o objetivo de avaliar o efeito de crescentes doses de N sobre as características morfogênicas do Panicum maximum Jacq cv. Tanzânia nas estações do ano, sob pastejo intermitente. Utilizou-se um delineamento em blocos ao acaso com parcelas subdivididas no tempo, com quatro repetições sendo os tratamentos: $\mathrm{N}_{1}=$ zero, $\mathrm{N}_{2}=150, \mathrm{~N}_{3}$ $=300$ e $\mathrm{N}_{4}=450 \mathrm{~kg} \cdot \mathrm{ha}^{-1}$ de nitrogênio e as estações do ano: outono, inverno, primavera e verão de 2008 e outono e inverno de 2009. No outono e inverno de 2009, os maiores comprimentos finais de lâminas foliares foram obtidos na maior dose de nitrogênio $(450 \mathrm{~kg})$. Tanto a taxa de aparecimento e alongamento de folhas responderam ao nitrogênio apresentando maiores taxas nas maiores doses de nitrogênio (300 e $450 \mathrm{~kg}$ ) e no verão, seguida de primavera contribuindo com a queda do filocrono e da duração de vida das folhas. Em geral, houve efeito das doses de nitrogênio assim como das estações avaliadas para as todas as variáveis morfogênicas.

PALAVRAS-CHAVE: Forragicultura. Morfogênese. Panicum maximum. Pastejo intermitente. Ureia.

\section{INTRODUÇÃO}

O capim-Tanzânia,cultivar do Panicum maximum Jacq., compõem uma proporção significativa da área de pastagens cultivadas no Brasil por geralmente apresentar uma alta produtividade e bom valor nutritivo quando bem adubadas e manejadas.

Para que se identifique a condição que maximiza a eficiência de produção, colheita e práticas de manejo de uma determinada espécie forrageira tornam-se cada vez mais necessárias informações das características estruturais e da morfogênese, ferramentas essenciais para a determinação das condições do pasto (altura, massa de forragem, massa de lâminas foliares, índice de área foliar) assegurando a produção animal eficiente e de forma sustentável (DA SILVA; NASCIMENTO JÚNIOR, 2006).

A morfogênese pode ser descrita a partir de três características básicas tais como, o aparecimento e alongamento de folhas e duração de vida de cada folha. Essas variáveis interagem entre si determinando as características estruturais do dossel: tamanho de folha, densidade populacional de perfilhos e número de folhas vivas por perfilho (LEMAIRE; CHAPMAN, 1996).
A relação direta da taxa de aparecimento foliar com a densidade de perfilhos determina o potencial de perfilhamento para um dado genótipo, pois cada folha formada sobre uma haste representa o surgimento de um novo fitômero, ou seja, a formação de uma nova gema axilar (NABINGER; PONTES, 2001), com potencial de geração de um novo perfilho (MATTHEW et al., 1999) contribuindo com melhorias da estrutura $\mathrm{e}$ produtividade da forrageira.

Apesar de essas características serem determinadas geneticamente, sofre grande influência de diversos outros fatores oriundos das estações do ano como o balanço hormonal, disponibilidade de luz, água, temperatura, estádio de desenvolvimento da planta (LEMAIRE; CHAPMAN, 1996) e disponibilidade de nutrientes (HERLING et al., 2001), sobretudo o nitrogênio, por seu efeito positivo no fluxo de biomassa (DURU; DUCROCQ, 2000)

Dentro deste contexto, o objetivo do trabalho foi avaliar a influência de doses crescentes de nitrogênio sobre as características morfogênicas em pastagem de Panicum maximum Jacq. cv. Tanzânia sob pastejo com lotação intermitente nas estações dos anos. 


\section{MATERIAL E MÉTODOS}

$\mathrm{O}$ experimento foi conduzido na Fazenda Experimental de Iguatemi (FEI), da Universidade Estadual de Maringá (UEM), Maringá-PR. A localização geográfica é $23^{\circ} 25^{\prime} \mathrm{S}$ de latitude e $51^{\circ}$ $57^{\prime} \mathrm{O}$ de longitude com uma altitude média de 550 metros. O tipo climático predominante desta região é o Cfa subtropical úmido mesotérmico, segundo a classificação de Köppen, com temperatura média anual de $22^{\circ} \mathrm{C}$. O período experimental ocorreu entre abril de 2008 a setembro de 2009 e os dados climáticos estão representados na Figura 1.

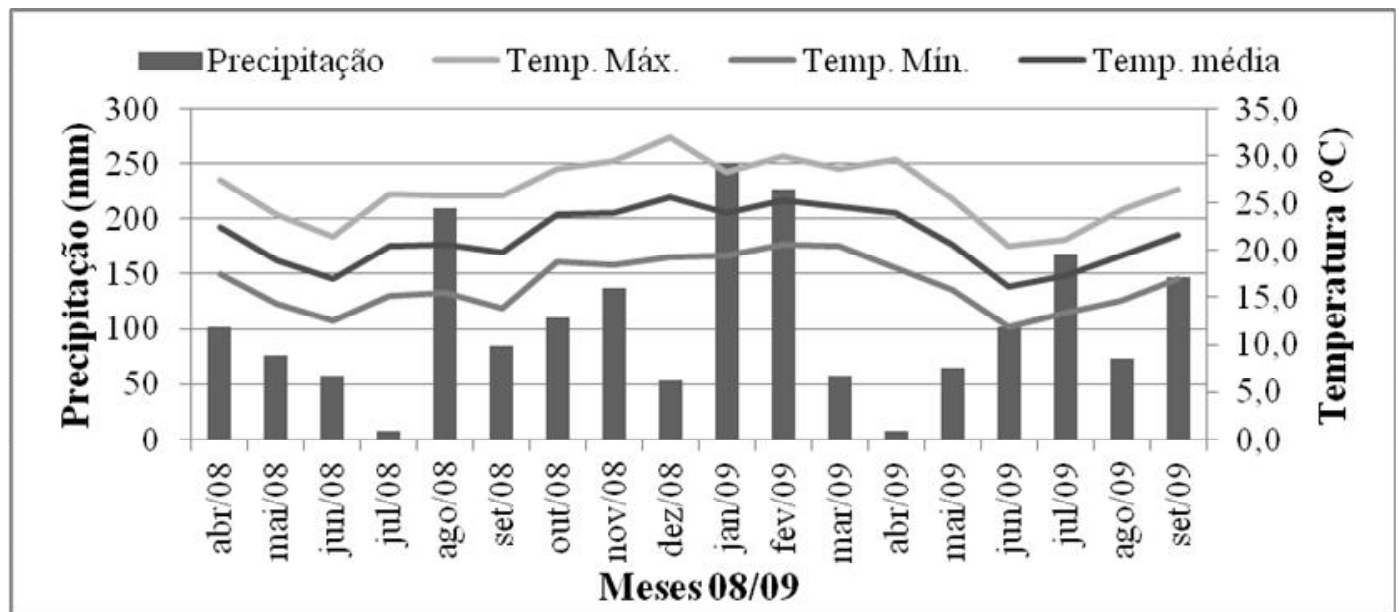

Figura 1. Condições climáticas obtidas durante o período experimental (Abril de 2008 a Setembro de 2009). Fonte: Laboratório de Sementes da FEI.

O experimento foi instalado em uma área estabelecida com Panicum maximum Jacq. cv. Tanzânia,com toda a infra-estrutura montada de cercas e bebedouros.

O solo da área experimental é classificado como Latossolo vermelho distrófico (EMBRAPA, 1999). No ano de 2007, foi realizada a correção da acidez no mês de junho com calcário dolomítico elevar a saturação por bases a $60 \%$, segundo Werner et al. (1996), A aplicação de $40 \mathrm{~kg} \cdot \mathrm{ha}^{-1}$ de $\mathrm{P}_{2} \mathrm{O}_{5}$ (superfosfato simples) e $60 \mathrm{~kg} \cdot \mathrm{ha}^{-1}$ de $\mathrm{K}_{2} \mathrm{O}$ (cloreto de potássio) foi realizado no final de setembro, onde no final de outubro de 2007, foram coletadas amostras de solo a uma profundidade de $0-10$ e 10 $20 \mathrm{~cm}$ de profundidade para posteriores análises química, obtendo-se os seguintes resultados: $\mathrm{pH}$ $\mathrm{H}_{2} \mathrm{O}=5,8 ; \mathrm{P}=17,33 \mathrm{mg} / \mathrm{dm}^{3} ; \mathrm{K}=0,12 \mathrm{cmolc} \mathrm{dm}^{-3}$; $\mathrm{H}^{+}+\mathrm{Al}^{+++}=3,17 \mathrm{cmolc} \mathrm{dm}^{-3} ; \mathrm{Al}=0,2 \mathrm{cmolc} \mathrm{dm}^{-3}$; $\mathrm{Ca}=1,3 \mathrm{cmolc} \mathrm{dm}^{-3} ; \mathrm{Mg}=0,63 \mathrm{cmolc} \mathrm{dm}^{-3} ; \mathrm{t}=6,0$ cmolc $\mathrm{dm}^{-3} ; \mathrm{CTC}=5,23 \mathrm{cmolc} \mathrm{dm}^{-3} ; \mathrm{SB}=2,05$ cmolc dm ${ }^{-3} ; \mathrm{V}=39,2 \%$.

Para o início do experimento, o pasto foi uniformizado a altura média de $35 \mathrm{~cm}$ em abril/2008 onde o nitrogênio $(\mathrm{N})$ foi parcelada em três aplicações por ano nas estações das águas, sendo $1 / 3$ no outono (31 de abril/2008), 1/3 na primavera ( 2 de outubro/2008) e 1/3 no verão (27 de fevereiro/2009) e uma última adubação na estação de outono (28 de maio/2009) para o encerramento do experimento, utilizando como fonte de $\mathrm{N}$ a uréia $(45 \%$ de $\mathrm{N})$.

$\mathrm{O}$ experimento consistiu de uma área de $1.600 \mathrm{~m}^{2}$ divididas em 16 piquetes com $100 \mathrm{~m}^{2}$ cada. Utilizou-se um delineamento em blocos casualizados com parcelas divididas no tempo, sendo as doses de nitrogênio: $\mathrm{N}_{1}=0, \mathrm{~N}_{2}=150, \mathrm{~N}_{3}=$ $300 \mathrm{e} \mathrm{N}_{4}=450 \mathrm{~kg} \mathrm{ha}^{-1} \mathrm{ano}^{-1}$ de $\mathrm{N}$ e quatro repetições consideradas como tratamentos principais e as estações dos anos como sub-parcela.

As estações foram definidas da seguinte forma: outono/08, inverno/, primavera/08, verão08/09, outono/09, e inverno/09 sendo este último avaliado até o corte de encerramento para todos os tratamentos ocorrendo em datas variadas, sendo dia 23 e 15 de setembro/09 para os tratamentos com 0 e $150 \mathrm{~kg}$ de $\mathrm{N}^{-1}$ ano $^{-1}$ e 4 de agosto $/ 09$ para os tratamentos com 300 e $450 \mathrm{~kg}$ de $\mathrm{N} \mathrm{ha}^{-1} \mathrm{ano}^{-1}$, respectivamente.

As parcelas foram pastejadas pelo método intermitente com entrada e saída dos animais quando o dossel da pastagem atingia 70 e $30 \mathrm{~cm}$ de altura, respectivamente. Foram utilizadas novilhas holandesas com peso médio de $250 \mathrm{~kg}$ para a realização do pastejo, as quais permaneciam no pasto por aproximadamente 22 horas, sendo os animais inseridos no período da manha (7 horas) e retirado no final da tarde (18 horas) e o mesmo era repetido no dia seguinte. 
Semanalmente foi realizada a mensuração da altura das plantas com régua graduada nas parcelas experimentais (leitura de 15 pontos representativos por parcela) até a pastagem atingir aproximadamente $70 \mathrm{~cm}$ de altura do solo.

Para a avaliação das características morfogênicas foram marcados 10 perfilhos representativos da pastagem, com arames, por unidade experimental, sendo cinco dentro e cinco ao redor da touceira, três dias após o rebaixamento da pastagem com os animais. Inicialmente foram mensurados o comprimento das lâminas foliares e a altura da lígula da primeira folha expandida, sendo este último avaliado para a aquisição do alongamento do colmo. Foram realizadas mensurações em intervalos de 4 dias para registrar o comprimento das lâminas foliares e o número de novas folhas surgidas em cada um dos perfilhos até a pastagem atingir aproximadamente $70 \mathrm{~cm}$ de altura do solo, sendo retiradas as hastes de arame e rebaixada novamente com os animais para a marcação de novos perfilhos e assim sucessivamente. Os dados foram digitados em planilha excell ${ }^{\circledR}$ para o cálculo das variáveis. A partir dessas informações, foram calculadas as seguintes variáveis:

Taxa de aparecimento de Folhas (TapF): Número de folhas surgidas por perfilho dividido pelo número de dias do período de avaliação folhas perfilho ${ }^{-1} \mathrm{dia}^{-1}$.

Filocrono (FIL): Inverso da taxa de aparecimento de folhas - dias folha ${ }^{-1}$ perfilho $^{-1}$.

Taxa de alongamento de Folhas (TalF): Somatório de todo alongamento da lâmina foliar por perfilho dividido pelo número de dias do período de avaliação $-\mathrm{cm}$ perfilho ${ }^{-1} \mathrm{dia}^{-1}$.

Duração de Vida de Folhas (DVF): Período de tempo entre o aparecimento de uma folha até sua morte. Estimada a partir da equação proposta por Lemaire e Chapman (1996): DVF = NFV x Filocrono (dias)

Número de Folhas Verdes (NFV): Número médio de folhas em alongamento e alongadas por perfilho desconsiderando folhas senescentes de cada perfilho.

Comprimento Final da Lâmina Foliar (CFLF): Comprimento médio de todas as folhas presentes no perfilho sendo medido do ápice foliar até a lígula $(\mathrm{cm})$.

Taxa de alongamento de Colmos (TalC): Somatório de todo alongamento de colmo/pseudocolmo por perfilho dividido pelo número de dias do período de avaliação $-\mathrm{cm}$ perfilho ${ }^{-1} \mathrm{dia}^{-1}$.
Taxa de senescência Foliar (TseF): senescência diária por perfilho ocorridas nas folhas $-\mathrm{cm} \mathrm{dia}^{-1}$

Em função do número de ciclos e intervalo de pastejo variável entre piquetes e tratamentos, os dados foram transformados em médias ponderadas, com base nas datas e duração de cada ciclo de pastejo.

A análise de variância foi realizada com o auxílio do pacote estatístico R (R, 2009), segundo o modelo:

$$
\mathbf{Y}_{\mathrm{ijk}}=\mu+\mathbf{T}_{\mathrm{i}}+\mathbf{P}_{\mathbf{j}}+\underset{\mathbf{k}}{\mathbf{B}}+\mathbf{T} \mathbf{P}_{\mathrm{ij}}+\mathbf{e}_{\mathrm{ijk}}
$$

Onde: $\mathrm{Y}_{\mathrm{ijk}}=$ valor da variável observada no bloco $\mathrm{k}$, coletada no período $\mathrm{j}$, recebendo o tratamento $\mathrm{i} ; \mu=$ média geral; $\mathrm{T}_{\mathrm{i}}=$ efeito do tratamento com $\mathrm{i}$ variando de 1 a $4 ; \mathrm{P}_{\mathrm{j}}=$ efeito devido ao período, com $\mathrm{j}$ variando de 1 a $6 ; \mathrm{B}_{\mathrm{k}}=$ efeito devido ao bloco com $\mathrm{k}$ variando de 1 a 4; $\mathrm{TP}_{\mathrm{ij}}=$ é o efeito da interação tratamento $\mathrm{x}$ período; $\mathrm{e}_{\mathrm{ijk}}=$ erro aleatório associado a cada observação. As médias foram comparadas pelo teste Tukey ao nível de significância de 5\%, utilizando-se o sistema computacional R (2009).

\section{RESULTADOS E DISCUSSÃO}

Durante todo o período experimental, foram constatados quatro cortes (pastejos) para a dose zero, cinco cortes para a dose $150 \mathrm{~kg} \mathrm{ha}^{-1}$ de $\mathrm{N}$ e seis cortes para as doses 300 e $450 \mathrm{~kg} \mathrm{ha}^{-1}$ de $\mathrm{N}$ conforme demonstrado na Figura 2.

Os resultados obtidos no presente estudo para Comprimento Final da Lâmina Foliar (CFLF), Taxa de aparecimento de Folhas (TapF), Taxa de alongamento de Folhas (TalF) e Filocrono (FIL) podem ser observados na Tabela 1.

Houve interação entre as doses de nitrogênio $(\mathrm{N})$ e estações dos anos para todas as variáveis analisadas. Em relação ao CFLF, nas estações de 2008, o N não modificou o CFLF das plantas, no entanto no outono e inverno de 2009 , este foi mais elevado no tratamento que recebeu a maior dose de $\mathrm{N}(450 \mathrm{~kg})$ em relação às plantas não adubadas e semelhante com os demais tratamentos. Este fato está associado à ação do $\mathrm{N}$ que em maior quantidade promove maior extensão das folhas das plantas nas referidas estações. Petry et al. (2005) ao avaliarem doses de $\mathrm{N}\left(0,100,200,300\right.$ e $400 \mathrm{~kg} \mathrm{ha}^{-1}$ de N) em cultivares de Panicum maximum, (Mombaça, Tanzânia e Millenium) também contataram efeito linear crescente sobre o CFLF, assim como Oliveira et al. (2007) relataram maior 
CFLF quando o capim-Tanzânia foi adubado com combinações contendo $\mathrm{N}$.

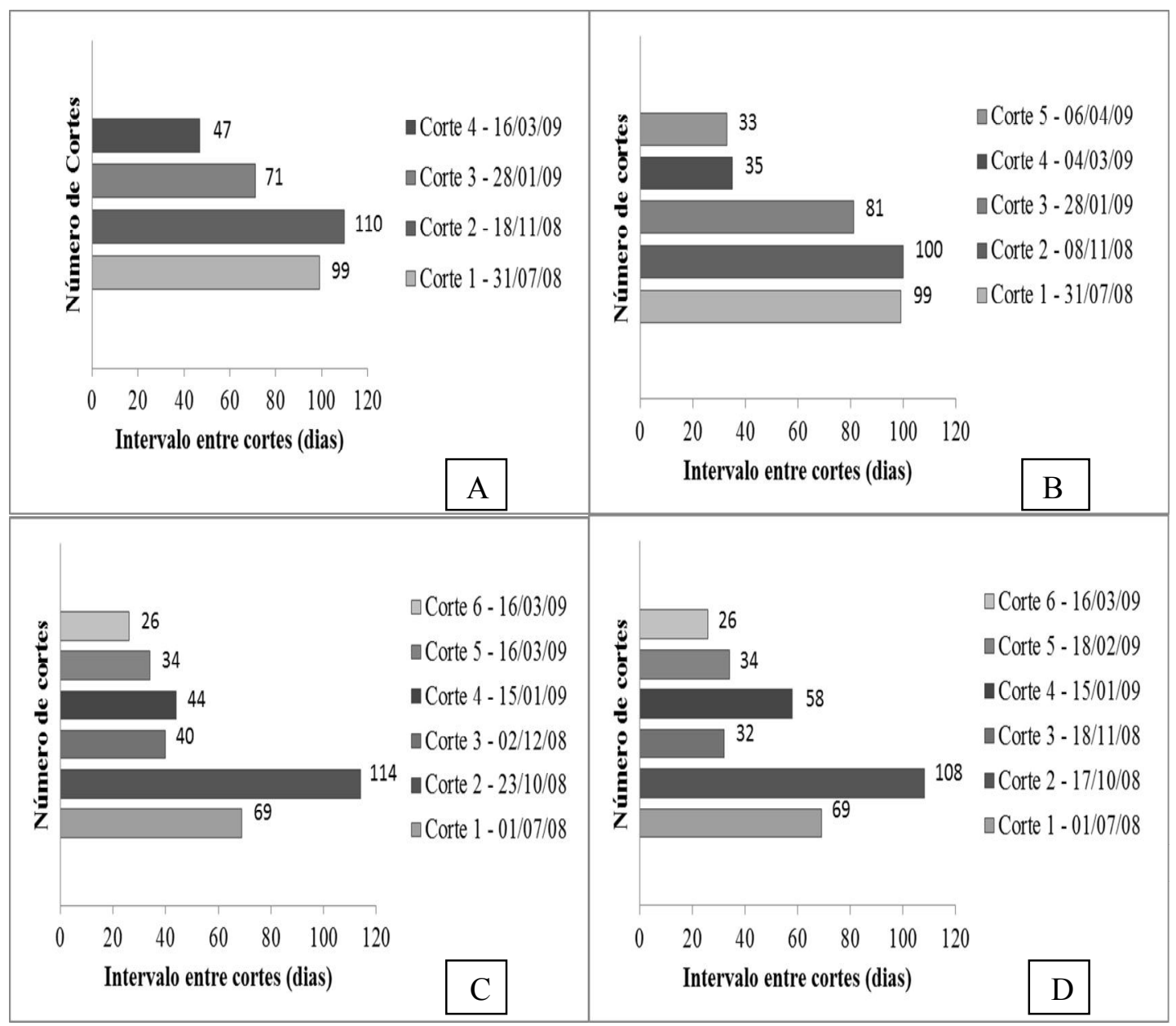

Figura 2. Número de cortes e intervalo entre cortes do capim-tanzânia ao longo do período experimental em função dos tratamentos avaliados. (A) $0 \mathrm{~kg} \mathrm{ha}^{-1} \mathrm{de} \mathrm{N}$; (B) $150 \mathrm{~kg} \mathrm{ha}^{-1} \mathrm{de} \mathrm{N}$; (C) $300 \mathrm{~kg} \mathrm{ha}^{-1}$ de N; (D) $450 \mathrm{~kg} \mathrm{ha}^{-1}$ de N. Início do experimento: 23/04/2008

Tabela 1. Médias do Comprimento Final de Lâminas Foliares $(\mathrm{cm})$, Taxa de aparecimento Foliar (folhas perfilho ${ }^{-1}$ dia $^{-1}$ ), Taxa de alongamento Foliar $\left(\mathrm{cm}\right.$ perfilho ${ }^{-1}$ dia $^{-1}$ ) e Filocrono (dias folha ${ }^{-1}$ perfilho ${ }^{-1}$ ) do capim-Tanzânia fertilizado com crescentes doses de nitrogênio nas estações dos anos, sob pastejo.

\begin{tabular}{|c|c|c|c|c|c|c|}
\hline \multirow[t]{3}{*}{ Estações } & \multicolumn{4}{|c|}{ Doses de N $\left(\mathrm{kg} \mathrm{ha}^{-1}\right.$ ano $\left.^{-1}\right)$} & \multirow[b]{3}{*}{ Média } & \multirow[b]{3}{*}{ DPM } \\
\hline & $\mathbf{0}$ & 150 & 300 & 450 & & \\
\hline & \multicolumn{4}{|c|}{ Comprimento final das lâminas foliares (cm) } & & \\
\hline outono-08 & $27,7^{\mathrm{A}^{*}}$ & 27,7 & $32,1^{\mathrm{A}}$ & $31,8^{\mathrm{A}}$ & 29,8 & 3,9 \\
\hline inverno-08 & $27,4^{\mathrm{A}}$ & 27,8 & $29,8^{\mathrm{AB}}$ & $27,7^{\mathrm{AB}}$ & 28,2 & 2,9 \\
\hline primavera-08 & $26,1^{\mathrm{AB}}$ & 26,8 & $26,6^{\mathrm{BC}}$ & $26,6^{\mathrm{B}}$ & 26,5 & 2,4 \\
\hline verão-08/09 & $25,1^{\mathrm{AB}}$ & 25,7 & $28,3^{\mathrm{ABC}}$ & $27,3^{\mathrm{AB}}$ & 26,6 & 2,8 \\
\hline outono-09 & $22,3^{\mathrm{bBC}}$ & $26,0^{\mathrm{ab}}$ & $24,7^{\mathrm{abc}}$ & $27,7^{\mathrm{aAB}}$ & 25,2 & 2,7 \\
\hline inverno-09 & $21,7^{\mathrm{bC}}$ & $26,0^{\mathrm{ab}}$ & $23,7^{\mathrm{ab} C}$ & $26,8^{\text {a B }}$ & 24,6 & 3,1 \\
\hline Média & 25,0 & 26,7 & 27,5 & 28,0 & & \\
\hline DPM & 3,0 & 2,5 & 4,3 & 3,0 & & \\
\hline
\end{tabular}




\begin{tabular}{|c|c|c|c|c|c|c|}
\hline & \multicolumn{4}{|c|}{ Taxa de aparecimento foliar (folhas perfilho ${ }^{-1} \mathrm{dia}^{-1}$ ) } & \multirow{2}{*}{$\frac{\text { Média }}{0,034}$} & \multirow{2}{*}{$\begin{array}{l}\text { DPM } \\
0,008\end{array}$} \\
\hline outono-08 & $0,033^{\mathrm{ab} \mathrm{C}}$ & $0,024^{\mathrm{bD}}$ & $0,041^{\text {a } \mathrm{C}}$ & $0,038^{\mathrm{aCD}}$ & & \\
\hline inverno-08 & $0,040^{\mathrm{C}}$ & $0,034^{\mathrm{C}}$ & $0,041^{\mathrm{C}}$ & $0,042^{\mathrm{C}}$ & 0,039 & 0,005 \\
\hline primavera-08 & $0,051^{\mathrm{cB}}$ & $0,050^{\mathrm{cB}}$ & $0,066^{\mathrm{b} \mathrm{B}}$ & $0,079^{\text {a B }}$ & 0,062 & 0,013 \\
\hline verão-08/09 & $0,077^{\mathrm{b} \mathrm{A}}$ & $0,086^{\mathrm{bA}}$ & $0,11^{\text {a A }}$ & $0,11^{\text {a A }}$ & 0,096 & 0,017 \\
\hline outono-09 & $0,025^{\mathrm{bD}}$ & $0,047^{\text {a C }}$ & $0,041^{\text {a C }}$ & $0,042^{\mathrm{aC}}$ & 0,039 & 0,009 \\
\hline inverno-09 & $0,018^{\mathrm{bD}}$ & $0,027^{\text {a D }}$ & $0,029^{\text {a D }}$ & $0,028^{\text {a D }}$ & 0,026 & 0,006 \\
\hline Média & 0,041 & 0,045 & 0,055 & 0,057 & & \\
\hline \multirow[t]{2}{*}{ DPM } & 0,020 & 0,022 & 0,029 & 0,030 & & \\
\hline & \multicolumn{4}{|c|}{ Taxa de alongamento foliar $\left(\mathrm{cm}\right.$ perfilho $\left.{ }^{-1} \mathrm{dia}^{-1}\right)$} & Média & DPM \\
\hline outono-08 & $1,01^{\mathrm{bBC}}$ & $1,38^{\text {ab B }}$ & $1,57^{\mathrm{aC}}$ & $1,52^{\text {a } \mathrm{C}}$ & 1,37 & 0,32 \\
\hline inverno-08 & $1,17^{\mathrm{BC}}$ & $1,44^{\mathrm{B}}$ & $1,38^{\mathrm{C}}$ & $1,18^{\mathrm{CD}}$ & 1,30 & 0,21 \\
\hline primavera-08 & $1,39^{\mathrm{b} \mathrm{B}}$ & $1,44^{\text {b B }}$ & $2,23^{\text {a B }}$ & $2,57^{\text {a B }}$ & 1,91 & 0,56 \\
\hline verão-08/09 & $2,42^{\mathrm{bA}}$ & $2,60^{\mathrm{bA}}$ & $3,97^{\text {a A }}$ & $3,66^{\text {a A }}$ & 3,16 & 0,74 \\
\hline outono-09 & $0,71^{\mathrm{bCD}}$ & $1,61^{\text {a B }}$ & $1,16^{\mathrm{ab} C D}$ & $1,31^{\text {a C }}$ & 1,20 & 0,36 \\
\hline inverno-09 & $0,43^{\mathrm{D}}$ & $0,78^{\mathrm{C}}$ & $0,72^{\mathrm{D}}$ & $0,77^{\mathrm{D}}$ & 0,68 & 0,18 \\
\hline Média & 1,19 & 1,54 & 1,84 & 1,84 & & \\
\hline \multirow[t]{2}{*}{ DPM } & 0,67 & 0,57 & 1,1 & 1,03 & & \\
\hline & \multicolumn{4}{|c|}{ Filocrono (dias folha $^{-1}$ perfilho $^{-1}$ ) } & Média & DPM \\
\hline outono-08 & $31,5^{\mathrm{ab} B C}$ & $44,0^{\text {a A }}$ & $24,7^{\mathrm{b} \mathrm{ABC}}$ & $26,5^{\mathrm{b} \mathrm{AB}}$ & 31,7 & 9,5 \\
\hline inverno-08 & $26,0^{\mathrm{BC}}$ & $35,0^{\mathrm{AB}}$ & $24,3^{\mathrm{ABC}}$ & $23,8^{\mathrm{AB}}$ & 27,3 & 5,8 \\
\hline primavera-08 & $35,8^{\text {a B }}$ & 22,4 ab BC & $17,9^{\mathrm{b} \mathrm{B}}$ & $15,3^{\mathrm{bB}}$ & 22,8 & 8,3 \\
\hline verão-08/09 & $16,5^{\mathrm{C}}$ & $13,3^{\mathrm{C}}$ & $10,5^{\mathrm{C}}$ & $11,6^{\mathrm{B}}$ & 13,0 & 2,5 \\
\hline outono-09 & $56,4^{\text {a A }}$ & $31,1^{\mathrm{b} A \mathrm{BB}}$ & $31,6^{\mathrm{b} A B}$ & $32,9^{\mathrm{b} \mathrm{A}}$ & 38,0 & 12,8 \\
\hline inverno-09 & $60,9^{\text {a A }}$ & $38,4^{\mathrm{b} \mathrm{A}}$ & $34,0^{\mathrm{bA}}$ & $35,6^{\mathrm{b} \mathrm{A}}$ & 42,2 & 13,4 \\
\hline Média & 37,8 & 30,7 & 23,8 & 24,3 & & \\
\hline DPM & 18,0 & 11,7 & 8,2 & 8,9 & & \\
\hline
\end{tabular}

*Médias com mesma letra minúscula na linha e maiúscula na coluna, não diferem entre si pelo teste de Tukey $(\mathrm{P}>0,05)$. DPM $=$ desvio padrão da média

Segundo Lemaire e Chapman, (1996), a influência do $\mathrm{N}$ sobre o CFLF pode ser explicado pela correlação entre o CFLF e a TalF. Tal fato presenciado no presente estudo, na qual maiores TalF foram obtidas nas maiores doses de $\mathrm{N}$ aplicados (300 e $450 \mathrm{~kg}$ ). Essa mais elevada TalF, contribui com maior CFLF, evidenciando a ação do $\mathrm{N}$, como promotor do processo de divisão celular estimulando a produção de novas células.

Segundo Garcez Neto et al. (2002), quando as plantas são submetidas a condições favoráveis de crescimento, a divisão celular também passa ser favorecida, possibilitando maiores lâminas foliares para mesmo comprimento de bainha. Segundo os autores, o aumento no tamanho de lâmina pode ser explicado pelo efeito simultâneo do N, que aumentou de forma expressiva o número de células em processo de divisão, e pela altura de corte, que determinou maior comprimento da bainha. $\mathrm{O} \mathrm{N}$, ao estimular a produção de novas células, possibilita aumento na TalF, o que pode constituir estratégia para mudanças no tamanho da lâmina foliar.

No tratamento com $150 \mathrm{~kg}$ de $\mathrm{N}$, não houve diferença entre as estações, já nas doses 0 e $300 \mathrm{~kg}$ de N, houve menor CFLF nas estações de outono e inverno de 2009, se comparado às demais estações de 2008, com exceção da primavera e verão, no tratamento com $300 \mathrm{~kg}$ de N. Essa redução nas devidas estações, provavelmente, foi ocasionada pela alta incidência de perfilhos reprodutivos na estação de outono/09 afetando o CFLF, onde boa parte dos nutrientes é voltada para o alongamento do entrenó e na emissão da inflorescência.

Com a aplicação do adubo nitrogenado, no geral, houve um incremento da TapF principalmente nas maiores doses avaliadas (300 e $450 \mathrm{~kg}$ ) e nas estações de maior crescimento do pasto (primavera e verão). Esse resultado reflete a importância do uso da adubação nitrogenada e principalmente quando 
associada às melhores condições de precipitação e temperatura (Figura 1).

Considerando as médias dos tratamentos ao longo das estações avaliadas, houve um incremento de $39 \%$ da TapF entre o tratamento sem $\mathrm{N}$ para a maior dose $(450 \mathrm{~kg}$ de N) com 0,041 e 0,057 folhas perfilho $^{-1} \mathrm{dia}^{-1}$, respectivamente. Esse aumento foi superior ao relatado por Roma et al., (2012), em experimento realizado na mesma área e espécie vegetal, que relatou um incremento de $28,5 \%$, todavia sendo $300 \mathrm{~kg}$ de $\mathrm{N}$ a maior dose avaliada. Os dados obtidos no presente experimento confirmam os dados obtidos por Patês et al. (2007) e Martuscello et al. (2005) que trabalhando com capim-Tanzânia e Xaraés, obtiveram aumento da TapF quando comparado à ausência de aplicação de N. Todavia, os valores obtidos no presente experimento foram inferiores aos obtidos pelos autores.

A adubação nitrogenada interfere intensamente na ativação dos tecidos meristemáticos (gemas axilares). Segundo Nabinger (1996), o déficit de $\mathrm{N}$ aumenta o número de gemas dormentes, enquanto o suprimento permite a formação de gemas vegetativas, elevando a TapF e, consequentemente, o perfilhamento de uma pastagem.

Segundo Garcez Neto et al. (2002), a taxa de alongamento foliar (TalF), quando suprida de $\mathrm{N}$, passa a ser a principal responsável na alteração da TapF, pois sucessivos aparecimentos de folhas sob níveis próximos de inserção, sob elevadas TalF suportadas pelo suprimento de $\mathrm{N}$, estabeleceriam maior TapF, sendo o $\mathrm{N}$ um grande diferencial para definir tanto a TapF quanto a TalF.

Para as estações de outono e inverno de 2009, foi constatado maior TapF para os tratamentos que receberam adubação nitrogenada em relação às plantas não adubadas com N. Fato este pode ter ocorrido em função da presença do adubo residual advindo da estação do verão e principalmente porque nestas estações a precipitação pluvial foi relativamente maior que nas mesmas estações de 2008 (Figura 1).

A TalF teve um comportamento semelhante à TapF, que confirma as observações relatadas por Grant et al. (1981), de que a TapF é largamente influenciada pela TalF sendo esta mais elevada no pasto adubado com as maiores doses de $\mathrm{N}(450 \mathrm{~kg})$, independentemente das estações de crescimento, exceto na dose de $150 \mathrm{~kg}$, que foi semelhante à aplicação de $300 \mathrm{~kg}$ de $\mathrm{N}$ nas estações de outono de 2008/09. De acordo com (GASTAL; NELSON, 1994), o aumento do alongamento foliar promovido pelo N, é atribuído ao fato da zona de alongamento ser um local ativo de grande demanda de nutrientes, principalmente o $\mathrm{N}$, ocorrendo maior produção de células na zona de divisão celular.

O incremento substancial na TalF de 55\% entre o tratamento sem $\mathrm{N}\left(1,19 \mathrm{~cm}\right.$ perfilho $\left.{ }^{-1} \mathrm{dia}^{-1}\right) \mathrm{e}$ a dose de $450 \mathrm{~kg}$ de $\mathrm{N}\left(1,84 \mathrm{~cm}_{\text {perfilho }}{ }^{-1} \mathrm{dia}^{-1}\right)$ considerando a média entre as estações avaliadas foi inferior se comparado com Garcez Neto et al. (2002), que obtiveram aumento médio de 52, 92 e

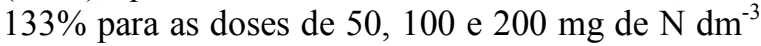
em Panicum maximum, cv. Mombaça. Entretanto, Martuscello et al. (2005), trabalhando com capimXaraés e Massai, observaram respectivos incrementos de até $37 \%$ e $64 \%$ na TalF $\left(\mathrm{cm} \mathrm{dia}^{-1}\right)$ na mais elevada dose de $\mathrm{N}\left(120 \mathrm{mg} \mathrm{dm}^{-3}\right)$, em comparação ao tratamento sem adubação nitrogenada, assim como Andrade et al. (2005) verificaram aumento de $41 \%$ na TAlF quando dobraram a adubação nitrogenada de 100 para 200 $\mathrm{kg} \mathrm{ha}^{-1}$ em capim-elefante irrigado.

Para as estações do ano, as maiores TalF ocorreram no verão, seguido da primavera, principalmente nas doses mais elevadas de N (300 e $450 \mathrm{~kg}$ ). Isto ocorreu porque nas estações, principalmente na primavera e verão, houve maior disponibilidade de umidade e boas condições de temperatura (Figura 1) e, que associado ao $\mathrm{N}$ promovem o incremento da TalF.

Santos et al. (2004), avaliando o capimMombaça (Panicum maximum cv. Mombaça) observaram maiores valores da TalF se comparado com o presente experimento, relatando valores de 1,$82 ; 1,5 ; 6,6$ e $9,5 \mathrm{~cm}^{2}$ perfilho ${ }^{-1} \mathrm{dia}^{-1}$ no outono, inverno, primavera e verão, respectivamente. Esta diferença é devido à variação genotípica entre as espécies avaliadas, uma vez que o capim-Mombaça proporciona maior produção de massa seca quando comparada com o capim-Tanzânia.

Segundo Martha Júnior. et al. (2004), o efeito do $\mathrm{N}$ tem sido bem relatado no aumento dos fatores que indicam crescimento (TalF, TapF) para as espécies referentes ao Panicum maximum, interferindo diretamente no aumento da produtividade da forrageira. $\mathrm{O}$ elemento atua diretamente sobre os aspectos morfofisiológicos da planta por fazer parte da estrutura das proteínas, da clorofila e de carreadores que participam de processos fisiológicos no vegetal. O FIL ou o inverso da TapF que indica o tempo (em dias ou em graus dia) necessário para o aparecimento de duas folhas consecutivas foi semelhante entre os tratamentos de $\mathrm{N}$ avaliados nas estações de verão e inverno/08, todavia, para as demais estações de crescimento, foi constatado menor FIL nos tratamentos que receberam adubação nitrogenada 
com exceção ao outono/08 e primavera que apresentaram resultados semelhantes entre $\mathrm{O}$ tratamento controle e $150 \mathrm{~kg}$ de N.

No geral, houve um decréscimo do FIL na medida em que houve aumento da adubação nitrogenada. A maior TapF e a mais elevada TalF permitiram redução no FIL à medida que se incrementou a adubação nitrogenada. Martuscello et al. (2006) trabalhando com capim-massai submetido a adubação nitrogenada e desfolhação, também constataram redução do FIL com o aumento das doses de N. Basso et al. (2010) trabalhando com capim-Milênio, apresentaram resposta quadrática com o aumento das doses de $\mathrm{N}$ sendo $37 \%, 50 \%$ e $40 \%$ menor para os tratamentos que receberam a adubação nitrogenada, com respectivamente 150,300 e $450 \mathrm{~kg}$ de $\mathrm{N}$ em relação aos piquetes que não receberam adubação $\mathrm{e}$ atingindo o ponto de máximo aos $310 \mathrm{~kg}$ de $\mathrm{N}$.
Martuscello et al. (2006) relata que a redução do FIL com a adubação nitrogenada, confere a planta à planta maior capacidade de rebrotação, visto que, após a desfolhação, uma rápida recuperação de seu aparato fotossintético pode possibilitar sua sobrevivência ou não na comunidade vegetal. Menores valores foram obtidos nas estações de maior crescimento da pastagem (primavera e verão) independentemente do tratamento estudado devido a maior rebrota (TapF) decorrente dessas estações oriundos das condições climáticas favoráveis de precipitação e temperatura (Figura 1).

Os resultados obtidos no presente estudo para o Número de Folhas Vivas (NFV), Duração de Vida das Folhas (DVF), Taxa de senescência Foliar (TseF) e Taxa de alongamento de Colmo (TalC) podem ser observados na Tabela 2.

Tabela 2: Médias do número de Folhas verdes, Duração de Vida das Folhas (dias), Taxa de senescência Foliar $\left(\mathrm{cm} \mathrm{dia}^{-1}\right)$ e Taxa de alongamento do Colmo $\left(\mathrm{cm}\right.$ perfilho $\left.{ }^{-1} \mathrm{dia}^{-1}\right)$ do capim-Tanzânia fertilizado com crescentes doses de nitrogênio nas estações dos anos, sob pastejo.

\begin{tabular}{|c|c|c|c|c|c|c|}
\hline \multirow[t]{3}{*}{ Estações } & \multicolumn{4}{|c|}{ Doses de N $\left(\mathrm{kg} \mathrm{ha}^{-1}\right.$ ano $\left.^{-1}\right)$} & \multirow[b]{3}{*}{ Média } & \multirow[b]{3}{*}{ DPM } \\
\hline & $\mathbf{0}$ & 150 & 300 & 450 & & \\
\hline & \multicolumn{4}{|c|}{ Número de folhas vivas } & & \\
\hline outono-08 & $4,8^{\mathrm{A}^{*}}$ & 5 & $4,7^{\mathrm{AB}}$ & $5,0^{\mathrm{AB}}$ & 4,9 & 0,5 \\
\hline inverno-08 & $4,9^{\mathrm{A}}$ & 5,3 & $5,4^{\mathrm{A}}$ & $4,9^{\mathrm{ABC}}$ & 5,1 & 0,6 \\
\hline primavera-08 & $5,1^{\mathrm{A}}$ & 5,2 & $5,3^{\mathrm{A}}$ & $4,8^{\mathrm{ABC}}$ & 5,1 & 0,5 \\
\hline verão-08/09 & $5,3^{\mathrm{A}}$ & 5 & $5,4^{\mathrm{A}}$ & $5,6^{\mathrm{A}}$ & 5,3 & 0,4 \\
\hline outono-09 & $3,1^{\text {b B }}$ & $4,8^{\text {a }}$ & $4,0^{\text {a B }}$ & $4,2^{\text {a BC }}$ & 4,0 & 0,8 \\
\hline inverno-09 & $2,8^{\mathrm{b} \mathrm{B}}$ & $4,7^{\mathrm{a}}$ & $3,8^{\text {a B }}$ & $4,0^{\text {a C }}$ & 3,8 & 0,9 \\
\hline Média & 4,32 & 5,0 & 4,8 & 4,8 & & \\
\hline \multirow[t]{2}{*}{ DPM } & 1,1 & 0,6 & 0,8 & 0,6 & & \\
\hline & \multicolumn{4}{|c|}{ Duração de vida das folhas (dias) } & Média & DPM \\
\hline outono-08 & $150^{\mathrm{bA}}$ & $214^{\mathrm{aA}}$ & $115^{\mathrm{b} A \mathrm{~B}}$ & $134^{\mathrm{bA}}$ & 153 & 44,1 \\
\hline inverno-08 & $125^{\mathrm{b} \mathrm{AB}}$ & $177^{\mathrm{a} A \mathrm{~B}}$ & $132^{\mathrm{bA}}$ & $124^{\mathrm{bA}}$ & 139 & 27,8 \\
\hline primavera-08 & $96^{\mathrm{ab} \mathrm{BC}}$ & $124^{\mathrm{aC}}$ & $90^{\mathrm{ab} \mathrm{BC}}$ & $77^{\mathrm{b} \mathrm{B}}$ & 97 & 19,1 \\
\hline verão-08/09 & $82^{\mathrm{C}}$ & $64^{\mathrm{D}}$ & $54^{\mathrm{C}}$ & $60^{\mathrm{B}}$ & 65 & 11,1 \\
\hline outono-09 & $152^{\mathrm{A}}$ & $144^{\mathrm{BC}}$ & $121^{\mathrm{AB}}$ & $124^{\mathrm{A}}$ & 135 & 17,6 \\
\hline inverno-09 & $161^{\mathrm{ab} \mathrm{A}}$ & $175^{\text {a } \mathrm{AB}}$ & $130^{\mathrm{bA}}$ & $136 b^{A}$ & 151 & 23,4 \\
\hline Média & 128 & 150 & 107 & 109 & & \\
\hline \multirow[t]{2}{*}{ DPM } & 34,4 & 51,4 & 29,6 & 31,1 & & \\
\hline & \multicolumn{4}{|c|}{ Taxa de senescência foliar $\left(\mathrm{cm} \mathrm{dia}^{-1}\right)$} & Média & DPM \\
\hline outono-08 & $0,12^{\mathrm{B}}$ & $0,15^{\mathrm{B}}$ & $0,18^{\mathrm{C}}$ & $0,17^{\mathrm{B}}$ & 0,15 & 0,04 \\
\hline inverno-08 & $0,13^{\mathrm{B}}$ & $0,14^{\mathrm{B}}$ & $0,15^{\mathrm{C}}$ & $0,17^{\mathrm{B}}$ & 0,15 & 0,03 \\
\hline primavera-08 & $0,15^{\mathrm{B}}$ & $0,15^{\mathrm{B}}$ & $0,16^{\mathrm{C}}$ & $0,24^{\mathrm{B}}$ & 0,17 & 0,07 \\
\hline verão-08/09 & $0,54^{\mathrm{ab} \mathrm{A}}$ & $0,39^{\mathrm{bA}}$ & $0,72^{\text {a A }}$ & $0,46^{\mathrm{b} A}$ & 0,53 & 0,19 \\
\hline outono-09 & $0,31^{\mathrm{B}}$ & $0,23^{\mathrm{AB}}$ & $0,39^{\mathrm{B}}$ & $0,30^{\mathrm{AB}}$ & 0,31 & 0,08 \\
\hline
\end{tabular}


Características morfogênicas...

IWAMOTO, B. S. et al.

\begin{tabular}{|c|c|c|c|c|c|c|}
\hline inverno-09 & $0,25^{\text {ab B }}$ & $0,11^{\mathrm{b} \text { B }}$ & $0,33^{\text {a BC }}$ & $0,26^{\mathrm{ab} A \mathrm{~B}}$ & 0,24 & 0,09 \\
\hline Média & 0,25 & 0,19 & 0,32 & 0,27 & & \\
\hline \multirow[t]{2}{*}{ DPM } & 0,17 & 0,13 & 0,21 & 0,12 & & \\
\hline & \multicolumn{4}{|c|}{ Taxa de alongamento do colmo $\left(\mathrm{cm}\right.$ perfilho ${ }^{-1}$ dia $\left.^{-1}\right)$} & Média & DPM \\
\hline outono-08 & $0,035^{\mathrm{A}}$ & $0,022^{\mathrm{AB}}$ & $0,029^{\mathrm{BC}}$ & $0,022^{\mathrm{B}}$ & 0,027 & 0,013 \\
\hline inverno-08 & $0,029^{\mathrm{A}}$ & $0,026^{\mathrm{AB}}$ & $0,031 \mathrm{~B}^{\mathrm{C}}$ & $0,016^{\mathrm{B}}$ & 0,025 & 0,011 \\
\hline primavera-08 & $0,023^{\mathrm{b} A B}$ & 0,031 ab A & $0,049^{a b} \mathrm{~B}$ & $0,075^{\text {a A }}$ & 0,044 & 0,025 \\
\hline verão-08/09 & $0,031^{\mathrm{b} \mathrm{A}}$ & $0,033^{\mathrm{bA}}$ & $0,113^{\text {a A }}$ & $0,096^{\text {a A }}$ & 0,068 & 0,04 \\
\hline outono-09 & $-0,005^{\mathrm{b} \text { BC }}$ & $0,005^{\mathrm{ab} \mathrm{AB}}$ & $0,011^{\mathrm{ab} C D}$ & $0,027^{\text {a B }}$ & 0,010 & 0,016 \\
\hline inverno-09 & $-0,010^{\mathrm{C}}$ & $-0,005^{\mathrm{B}}$ & $-0,007^{\mathrm{D}}$ & $0,005^{\mathrm{B}}$ & $-0,004$ & 0,009 \\
\hline Média & 0,017 & 0,019 & 0,038 & 0,040 & & \\
\hline DPM & 0,022 & 0,018 & 0,040 & 0,036 & & \\
\hline
\end{tabular}

*Médias com mesma letra minúscula na linha e maiúscula na coluna, não diferem entre si pelo teste de Tukey $(\mathrm{P}>0,05)$. DPM $=$ desvio padrão da média

Houve interação entre as doses de nitrogênio $(\mathrm{N})$ e estações dos anos. Para o NFV, não se verificou a influência do $\mathrm{N}$ nas estações de 2008, todavia, houve efeito do $\mathrm{N}$ nas estações de outono e inverno de 2009 ocorrendo maior NFV para os tratamentos que receberam adubação nitrogenada $(150,300$ e $450 \mathrm{~kg})$, com aumento de $35 \%$ e $45 \%$ da menor para a maior dose de $\mathrm{N}$ aplicada nas respectivas estações. Segundo Oliveira et al. (2007) o NFV pode estar associado ao estímulo do $\mathrm{N}$ à produção de novos tecidos. Silveira \& Monteiro (2007) também verificaram que as doses de $\mathrm{N}$ influenciaram positivamente no número total de folhas em capim-Tanzânia adubado com nitrogênio e cálcio.

Nas estações, observa-se efeito nos tratamentos com 0,300 e $450 \mathrm{~kg}$ de $\mathrm{N}$ em que se constata menor NFV nas estações de outono e inverno de 2009. Esse menor NFV encontrado nessas estações pode ser oriundo da alta incidência de perfilhos reprodutivos, pois a planta dá prioridades ao uso dos nutrientes para o alongamento do entrenó e posteriormente ocorrendo a emissão da inflorescência afetando consequentemente a TalF, TapF e o CFLF além de que, em geral, nas estações de outono e inverno de 2009 e no verão de 2008 ocorreu um aumento no valor da TseF (Tabela 3), contribuindo com a redução do NFV.

O maior valor de NFV ocorreu durante as estações de 2008, épocas em que houve condições climáticas favoráveis (Figura 1) ao crescimento dos perfilhos, corroborando com Fagundes et al. (2006) que apresentaram resultados similares sobre a influência das estações do ano no NFV. Variações nessa característica assim como do CFLF determinam mudanças na estrutura e composição morfológica da pastagem.
Para DVF, com exceção do verão e outono/09, houve efeito da adubação nitrogenada, promovendo maior DVF na dose com $150 \mathrm{~kg}$ de N. Todavia, esta foi semelhante à dose de $300 \mathrm{~kg}$ de $\mathrm{N}$ e nas plantas não adubadas na primavera $\mathrm{e}$ inverno/09. No geral, a DVF nas estações em que houve efeito dos tratamentos não ficou de maneira elucidativa no presente experimento. Segundo Martuscello et al., (2005) o $\mathrm{N}$ favorece no decréscimo da DVF em detrimento da maior renovação de tecidos evidenciado pela TalF e maior TapF. Corroborando com os dados obtidos por Basso et al. (2010) que constatou redução da DVF conforme o aumento da adubação nitrogenada em e Panicum maximum Jacq. cv. IPR-86 Milênio. Todavia, Roma et al. (2012) não constatou o efeito do N na redução da DVF para o capim-Tanzânia.

Em relação às estações avaliadas, constatouse menor DVF no verão seguido de primavera, independente da dose de $\mathrm{N}$ utilizada, com exceção da maior dose $(450 \mathrm{~kg})$, em que ambas as estações apresentaram resultados semelhantes. A redução da DVF na primavera e verão pode ser explicada pela maior TalF e TapF devido as melhores condições climáticas e, por conseguinte, um menor filocrono além de uma maior TseF, ambos contribuindo com a redução da DVF.

A TseF foi maior no tratamento com $300 \mathrm{~kg}$ de $\mathrm{N}$ nas estações de verão e inverno/09, porém nestas foi semelhante às plantas não adubadas e também no inverno/09 foi semelhantes à adubação com $450 \mathrm{~kg}$ de $\mathrm{N}$.

A TseF das plantas em função do $\mathrm{N}$ aplicado pode haver efeitos variados, onde Fagundes et al. (2006), não constataram mudanças na TseF sob o efeito de diferentes doses de N. Contudo, Martuscello et al., (2005) e Mazzanti et 
al., (1994) evidenciam os efeitos do $\mathrm{N}$ na redução da TseF.

Nas estações, verificou-se a maior TseF na estação de verão, porém esta sendo semelhante ao outono/08 e outono e inverno de 2009, na maior e menor dose de $\mathrm{N}$, respectivamente. Provavelmente, o maior fluxo de tecido (TalF, TapF) no verão pode ser oriundo da maior assimilação do adubo $\mathrm{N}$ e das condições favoráveis de luminosidade, precipitação e temperatura, elevando a TseF. Resultados relatados por Fagundes et. al. (2006) mostram maiores TseF na estação de primavera, possivelmente em razão da maior idade média das folhas nesse período.

Foi observado que o intervalo entre pastejo em função dos tratamentos impostos não afetou a TseF apresentando média de $\left(0,26 \mathrm{~cm} \mathrm{dia}^{-1}\right)$. Todavia, Santos et al. (2004), avaliando o capimmombaça submetido a três intervalos de pastejo, verificaram que a TseF foi maior com 48 dias de intervalo de pastejo $(2,07 \mathrm{~cm} /$ perfilho.dia) seguido de 38 dias $\left(1,17 \mathrm{~cm}_{\text {perfilho }}{ }^{-1} \mathrm{dia}^{-1}\right)$ e 28 dias $(0,74$ cm perfilho $\left.{ }^{-1} \mathrm{dia}^{-1}\right)$. Dados esses superiores ao relatado no presente estudo, porém os valores obtidos no presente experimento foram próximos ao relatado por Roma et al. (2012) com $(0,31 \mathrm{~cm}$ perfilho $^{-1} \mathrm{dia}^{-1}$ ).

A TseF é um dos fatores mais importantes quando se trabalha o processo de acúmulo massa de forragem à produção animal, pois esta determina o acúmulo líquido de massa de forragem por área.

A TalC foi semelhante entre as doses de $\mathrm{N}$ para as estações de outono e inverno de 2008 e inverno/09, enquanto que esta foi mais elevada na maior dose de $\mathrm{N}$ (450 kg) nas estações da primavera e verão de 2008 e outono de 2009 , em relação às não adubadas e apenas diferente da adubada com a menor dose de $\mathrm{N}$ no verão.

O maior alongamento obtido nas maiores doses indica que a adubação nitrogenada favorece o alongamento de colmo promovendo um aumento de $226 \%$, 209\%, e 640\% da menor (sem adubação) para a maior dose $(450 \mathrm{~kg}$ de $\mathrm{N})$ para as estações de primavera, verão e outono/09, respectivamente. Em geral, esse maior alongamento na estação de verão seguida de primavera se deve às condições ambientais favoráveis, como luz, temperatura e, principalmente, disponibilidade de água, visto que as maiores precipitações pluviais foram registradas neste período (Figura 1), potencializado pelo adubo nitrogenado.
Houve redução na TalC no tratamento controle nas estações de outono e inverno de 2009 e na dose com $150 \mathrm{~kg}$ de $\mathrm{N}$ no inverno/09,tal fato pode ser oriundo da morte das folhas com as lígulas expostas que estavam na parte superior do perfilhos, haja vista que a determinação da TalC foi em função da altura da lígula da última folha expandida.

Patês et al. (2007) avaliando as características morfogênicas e estruturais do capimTanzânia submetido a doses de fósforo e nitrogênio, verificou aumento da TalC para o tratamento recendo o adubo nitrogenado independente da dose de fósforo avaliada.

Segundo Santos (2002), um dos grandes problemas no manejo do capim-Tanzânia é o aumento na participação dos colmos. O alongamento do colmo em função da época de florescimento apresenta efeito indesejável na qualidade da forragem, pela diminuição da relação lâmina-colmo, reduzindo, assim, o valor nutritivo da forragem.

Como mencionado anteriormente, Duru \& Ducrocq (2000) relatam que, quanto maior o comprimento do colmo, maior será o CFLF, pois maior será a fase de multiplicação celular e mais tempo a folha que está em expansão ficará protegida da luz na bainha (DAVIES et al., 1983), o que pôde ser observado neste experimento, em que a TalC e o CFLF obtiveram aumentos respondendo de forma positiva a adubação nitrogenada.

A TalC foi muito mais baixa nas estações de inverno e outono de 2008 e no inverno de 2009 em relação às outras, independentemente da aplicação ou não de $\mathrm{N}$, oque confirma relatos de literatura, que em condições não adequadas, as plantas reduzem a TapF (Tabela 2), mas preferencialmente emitem folhas em detrimento à formação e alongamento do colmo.

Embora o desenvolvimento do colmo propicie aumentos significativos à produção de massa seca de forragem, ele pode influenciar negativamente o valor nutritivo da forragem, além de aumentar o intervalo de aparecimento de folhas.

Para todas as variáveis morfogênicas, foi realizado um desdobramento da interação considerando o comportamento da variável em função de época, dentro de cada dose de nitrogênio avaliado no presente experimento (Tabela 3) para possíveis avaliações e simulações de valores em doses equivalentes no intervalo de zero a $450 \mathrm{~kg}$ de $\mathrm{N} \mathrm{ha}^{-1}$ ano $^{-1}$. 
Tabela 3. Desdobramento da interação das variáveis morfogênicas considerando o comportamento da variável em função de época, dentro de cada dose de nitrogênio.

\begin{tabular}{|c|c|c|c|c|c|c|c|c|c|}
\hline Variável & $\begin{array}{c}\text { Doses } \\
\text { de N }\end{array}$ & & $\mathrm{b}_{0}$ & $b_{1}$ & $b_{2}$ & $b_{3}$ & $\mathrm{~b}_{4}$ & $b_{5}$ & $\mathrm{R}^{2}$ \\
\hline \multirow{4}{*}{ TFF } & 0 & $\mathrm{Y}=$ & 29,66 & $-1,32 * b 1$ & ns & ns & ns & ns & 0,57 \\
\hline & 150 & $\mathrm{Y}=$ & 28,14 & $-0,43 * b 1$ & ns & ns & ns & ns & 0,09 \\
\hline & 300 & $\mathrm{Y}=$ & 33,05 & $-1,58 * \mathrm{~b} 1$ & ns & ns & ns & ns & 0,41 \\
\hline & 450 & $\mathrm{Y}=$ & 40,58 & $-11,56^{*} \mathrm{~b} 1$ & $+3,07 * \mathrm{~b} 2$ & $-0,25 * b 3$ & ns & ns & 0,37 \\
\hline \multirow{4}{*}{ Fil } & 0 & $\mathrm{Y}=$ & $-33,23$ & $+117,34 * b 1$ & $-67,51 * b 2$ & $+14,68^{*} \mathrm{~b} 3$ & $-1,04 * b 4$ & ns & 0,60 \\
\hline & 150 & $\mathrm{Y}=$ & $-5,58$ & $+98,50 * \mathrm{~b} 1$ & $-61,62 * b 2$ & $+13,30 * \mathrm{~b} 3$ & $-0,93 * b 4$ & ns & 0,76 \\
\hline & 300 & $\mathrm{Y}=$ & $-45,95$ & $+128,68 * \mathrm{~b} 1$ & $-72,86 * \mathrm{~b} 2$ & $+15,47^{*} \mathrm{~b} 3$ & $-1,09 * \mathrm{~b} 4$ & $\mathrm{~ns}$ & 0,87 \\
\hline & 450 & $\mathrm{Y}=$ & $-38,74$ & $+122,80 * \mathrm{~b} 1$ & $-72,50 * \mathrm{~b} 2$ & $+15,81 * \mathrm{~b} 3$ & $-1,13 * b 4$ & ns & 0,93 \\
\hline \multirow{4}{*}{ TapF } & 0 & $\mathrm{Y}=$ & 0,18 & $-0,27 * b 1$ & $+0,15 * \mathrm{~b} 2$ & $-0,033 * b 3$ & $+0,002 * \mathrm{~b} 4$ & ns & 0,78 \\
\hline & 150 & $\mathrm{Y}=$ & 0,14 & $-0,21 * b 1$ & $+0,12 * \mathrm{~b} 2$ & $-0,025 * \mathrm{~b} 3$ & $+0,002 * \mathrm{~b} 4$ & ns & 0,83 \\
\hline & 300 & $\mathrm{Y}=$ & 0,31 & $-0,48 * b 1$ & $+0,27 * \mathrm{~b} 2$ & $-0,055^{*} \mathrm{~b} 3$ & $+0,004 * \mathrm{~b} 4$ & ns & 0,82 \\
\hline & 450 & $\mathrm{Y}=$ & 0,3 & $-0,49 * \mathrm{~b} 1$ & $+0,28 * \mathrm{~b} 2$ & $-0,058 * b 3$ & $+0,004 * \mathrm{~b} 4$ & ns & 0,91 \\
\hline \multirow{4}{*}{ TalF } & 0 & $\mathrm{Y}=$ & 5,91 & $-8,85 * b 1$ & $+4,97 * \mathrm{~b} 2$ & $-1,04 * b 3$ & $+0,072 * b 4$ & ns & 0,70 \\
\hline & 150 & $\mathrm{Y}=$ & 3,96 & $-4,37 * b 1$ & $+2,21 * \mathrm{~b} 2$ & $-0,40 * b 3$ & $+0,023 * \mathrm{~b} 4$ & ns & 0,70 \\
\hline & 300 & $\mathrm{Y}=$ & 12,38 & $-19,22 * b 1$ & $+10,49 * \mathrm{~b} 2$ & $-2,15 * b 3$ & $+0,147 * \mathrm{~b} 4$ & ns & 0,79 \\
\hline & 450 & $\mathrm{Y}=$ & 12,4 & $-19,47 * b 1$ & $+10,68 * b 2$ & $-2,20 * b 3$ & $+0,151 * \mathrm{~b} 4$ & ns & 0,90 \\
\hline \multirow{4}{*}{ NFV } & 0 & $\mathrm{Y}=$ & 10,28 & $-10,14 * b 1$ & $+5,90 * \mathrm{~b} 2$ & $-1,30 * b 3$ & $+0,094 * \mathrm{~b} 4$ & ns & 0,81 \\
\hline & 150 & $\mathrm{Y}=$ & 5,31 & $-0,09 * \mathrm{~b} 1$ & ns & ns & ns & ns & 0,06 \\
\hline & 300 & $\mathrm{Y}=$ & 2,75 & $+128,68 * \mathrm{~b} 1$ & $-0,68 * b 2$ & $+0,049 * \mathrm{~b} 3$ & ns & ns & 0,66 \\
\hline & 450 & $\mathrm{Y}=$ & 8,81 & $-6,58 * b 1$ & $+3,50 * \mathrm{~b} 2$ & $-0,72 * b 3$ & $+0,049 * \mathrm{~b} 4$ & ns & 0,47 \\
\hline \multirow{4}{*}{ TseF } & 0 & $\mathrm{Y}=$ & 0,98 & $-1,47 * \mathrm{~b} 1$ & $+0,75 * \mathrm{~b} 2$ & $-0,14 * b 3$ & $+0,008 * \mathrm{~b} 4$ & ns & 0,54 \\
\hline & 150 & $\mathrm{Y}=$ & 0,39 & $-0,38 * b 1$ & $+0,16 * \mathrm{~b} 2$ & $-0,017 * b 3$ & ns & ns & 0,41 \\
\hline & 300 & $\mathrm{Y}=$ & 1,58 & $-2,36 * b 1$ & $+1,18 * \mathrm{~b} 2$ & $-0,22 * b 3$ & $+0,013 * \mathrm{~b} 4$ & ns & 0,64 \\
\hline & 450 & $\mathrm{Y}=$ & 0,89 & $-1,27 * b 1$ & $+0,67 * \mathrm{~b} 2$ & $-0,13 * b 3$ & $+0,008 * \mathrm{~b} 4$ & ns & 0,60 \\
\hline \multirow{4}{*}{ DVF } & 0 & $\mathrm{Y}=$ & $-21,24$ & $+337,93 * \mathrm{~b} 1$ & $-212,28 * b 2$ & $+47,49 * b 3$ & $-3,44 * b 4$ & ns & 0,74 \\
\hline & 150 & $\mathrm{Y}=$ & $-24,19$ & $+461,98 * \mathrm{~b} 1$ & $-280,40 * \mathrm{~b} 2$ & $+59,04 * \mathrm{~b} 3$ & $-4,03 * b 4$ & ns & 0,83 \\
\hline & 300 & $\mathrm{Y}=$ & $-235,9$ & $+621,78 * \mathrm{~b} 1$ & $-336,16 * b 2$ & $+68,78^{*} \mathrm{~b} 3$ & $-4,72 * b 4$ & ns & 0,82 \\
\hline & 450 & $\mathrm{Y}=$ & $-116,5$ & $+470,34 * \mathrm{~b} 1$ & $-275,67 * b 2$ & $+59,08 * \mathrm{~b} 3$ & $-4,17 * b 4$ & $\mathrm{~ns}$ & 0,91 \\
\hline \multirow{4}{*}{ TalC } & 0 & $\mathrm{Y}=$ & 0,13 & $-0,17 * \mathrm{~b} 1$ & $+0,088 * \mathrm{~b} 2$ & $-0,019 * \mathrm{~b} 3$ & $+0,0013 * \mathrm{~b} 4$ & ns & 0,64 \\
\hline & 150 & $\mathrm{Y}=$ & 0,004 & $+0,020^{*} \mathrm{~b} 1$ & $-0,0036 * b 2$ & ns & ns & ns & 0,56 \\
\hline & 300 & $\mathrm{Y}=$ & 0,359 & $-0,59 * b 1$ & $+0,33 * \mathrm{~b} 2$ & $-0,067 * b 3$ & $+0,0046^{*} \mathrm{~b} 4$ & ns & 0,73 \\
\hline & 450 & $\mathrm{Y}=$ & 0,364 & $-0,62 * b 1$ & $+0,35^{*} \mathrm{~b} 2$ & $-0,07 * b 3$ & $+0,005 * \mathrm{~b} 4$ & $\mathrm{~ns}$ & 0,88 \\
\hline
\end{tabular}

* ns = não-significativo. bo = intercepto; b1 = coeficiente de regressão linear; b2 = coeficiente de regressão quadrática; b3 = coeficiente de regressão cúbica; b4 = coeficiente de regressão quártica; b5 = coeficiente de regressão quíntica.

\section{CONCLUÕES}

As características morfogênicas do capimTanzânia são influenciadas pelas doses de nitrogênio, exercendo efeito positivo nas taxas de aparecimento e alongamento de folhas.
Independentemente da dose de $\mathrm{N}$ avaliada, maiores taxas de aparecimento e alongamento de folhas são obtidas no verão, seguida de primavera.

A estação de verão acelera o ritmo morfogênico da pastagem, reduzindo a duração de vida das folhas por elevar a taxa de senescência 
foliar, além de contribuir no aumento do alongamento do colmo nas plantas.

A adubação nitrogenada associada às condições climáticas favoráveis na primavera e verão favorece no maior aparecimento e alongamento das folhas, fatores que melhoram o valor nutritivo, favorecendo o desempenho animal individual e produção por unidade de área.

\begin{abstract}
The experiment was conducted at the Experimental Farm of Iguatemi - UEM, from April 2008 to September 2009 in order to evaluate the effect of increasing doses of nitrogen on the morphogenesis of Panicum maximum cv. Tanzania in the seasons of the year under intermittent grazing. It was used a randomized block design with split plot with four replications and the treatments: $\mathrm{N} 1=$ zero, $\mathrm{N} 2=150, \mathrm{~N} 3=300$ and N4 $=450 \mathrm{~kg}$ of N.ha ${ }^{-1}$ and the seasons: autumn, winter, spring and summer of 2008 and autumn and winter of 2009. In autumn and winter of 2009, the largest final lengths of leaf blade were obtained at the highest nitrogen dose $(450 \mathrm{~kg})$. In the fall and winter of 2009 , the largest final leaf blade length was obtained at the highest dose of nitrogen $(450 \mathrm{~kg})$. Both the leaf appearance and elongation rate responded to nitrogen with higher rates at higher nitrogen doses (300 and $450 \mathrm{~kg}$ ) and in summer, followed by spring contributing to the fall of phyllochron and life span of leaves. In general, there was effect of nitrogen doses as well as the stations evaluated for all variables analyzed.
\end{abstract}

KEYWORDS: Foraging. Morphogenesis. Panicum maximum. Intermittent grazing. Urea.

\title{
REFERÊNCIAS
}

ANDRADE, A. C.; FONSECA, D. M.; LOPES, R. S.; NASCIMENTO JR., D.; CECON, P. R.; QUEIROZ, D. S.; PEREIRA, D. H.; REIS, S. T. Características morfogênicas e estruturais do Capim-elefante 'Napier' adubado e irrigado. Ciência e Agrotecnologia, Lavras, v. 29, n. 1, p. 150-159, jan./fev.2005.

BASSO, K. C.; CECATO, U.; LUGÃO, S. M. B; GOMES J. A. N.; BARBERO, L. M.; MOURÃO, G. B. Morfogênese e dinâmica do perfilhamento em pastos de Panicum maximum Jacq. cv. IPR-86 Milênio submetido a doses crescentes de nitrogênio. Revista Brasileira de Saúde e Produção Animal, Salvador, v. 11, n. 4, p. 976-989, out./dez. 2010.

DA SILVA, S. C.; NASCIMENTO JÚNIOR, D. Ecofisiologia de Plantas Forrageiras. In: PEREIRA, O. G., OBEID, J. A., NASCIMENTO Jr., D. FONSECA, D. M., (Eds.). Simpósio sobre Manejo Estratégico da Pastagem, III, Viçosa, 2006. Anais... Viçosa: Universidade Federal de Viçosa, 2006. p. 1-42, 430p.

DAVIES, A.; EVANS, M. E.; EXLEY, J. K. Regrowth of perennial ryegrass as affected by simulated leaf sheaths. Journal Agriculture Science, Cambridge, v. 101, n. 1, p. 131-137, 1983.

http://dx.doi.org/10.1017/S0021859600036455

DURU, M.; DUCROCQ, H. Growth and senescence of the sucessive leaves on a Cocksfoot tiller. Effect of nitrogen and cutting regime. Annals of Botany, Oxford, v. 85, p. 645-653, 2000.

http://dx.doi.org/10.1006/anbo.1999.1117

EMBRAPA - EMPRESA BRASILEIRA DE PESQUISA AGROPECUÁRIA. Sistema brasileiro de classificação de solos. Rio de Janeiro: Embrapa Solos, 1999. 171p.

FAGUNDES, J. L.; FONSECA, D. M.; MISTURA, C.; MORAIS, R. V.; VITOR, C. M. T; GOMIDE, J. A.; NASCIMENTO JR, D.; COSTA, L. T. Características morfogênicas e estruturais do capim-braquiária em pastagem adubada com nitrogênio avaliadas nas quatro estações do ano. Revista Brasileira de Zootecnia, Viçosa, v. 35, n. 1, p. 21-29, jan./fev. 2006.

GARCEZ NETO, A. F.; NASCIMENTO JÚNIOR, D.; REGAZZI, A. J.; FONSECA, D. M.; MOSQUIM, P. R.; GOBBI, K. F. Respostas morfogênicas e estruturais de Panicum maximum cv. Mombaça sob diferentes níveis de adubação nitrogenada e alturas de corte. Revista Brasileira de Zootecnia, Viçosa, v. 31, n. 5, p. 1890-1900, set./out. 2002. 
GASTAL, F.; NELSON, C. J. Nitrogen use whitin the growing leaf blade of tall fescue. Plant Physiology, Rockville, v. 105, p. 191-197, may. 1994.

GRANT, S. A.; BARTHRAM, G. T.; TORVEL, L. Components of regrowth in grazed and cut Lolium perenne swards. Grass and Forage Science, Oxford, v. 36, p. 155-168, 1981. http://dx.doi.org/10.1111/j.1365-

2494.1981.tb01552.x

HERLING, V. R.; BRAGA, G. J.; LUZ, P. H. C.; OTANI, L. Tanzânia e Mombaça. In: SIMPÓSIO SOBRE MANEJO DA PASTAGEM. FEALQ, Piracicaba, 2001. 17 p.89-134.

LEMAIRE, G.; CHAPMAN, D. Tissue flows in grazed plant communities. In: HODGSON, J.; ILLIUS, A. W. (Eds.). The ecology and management of grazing systems. Wallingford:CAB International, 1996, p. 3-36.

MARTHA JÚNIOR, G. B.; CORSI, M.; OCHEUZE, P. C. T.;. VILELA, L.; PINTO, T. L. F.; TEIXEIRA, G. M.; MANZONI, C. S.; BARIONI, L. G. Perda de Amônia por Volatilização em Pastagem de Capim-tanzânia Adubada com Uréia no Verão. Revista Brasileira de Zootecnia, Viçosa, v. 33, n. 6, p. 2240-2247, 2004.

MARTUSCELLO, J. A.; FONSECA, D. M.; NASCIMENTO JR., D.; SANTOS, P. M.; CUNHA, D. N. F. V.; MOREIRA, L. M. Características morfogênicas e estruturais de capim-Massai submetido a adubação nitrogenada e desfolhação. Revista Brasileira de Zootecnia, Viçosa, v. 35, n. 3, p. 665-671, 2006.

MARTUSCELLO, J. A.; FONSECA, D. M.; NASCIMENTO JR., D.; SANTOS, P. M.; CUNHA, D. N. F. V.; MOREIRA, L. M. Características morfogênicas e estruturais do capim-Xaraés submetido à adubação nitrogenada e desfolhação. Revista Brasileira de Zootecnia, Viçosa, v. 34, n. 5, p. 1475-1482, 2005.

MATTHEW, C.; ASSUERO, S. G.; BLACK, C. K.; HAMILTON, N. R. S. Tiller dynamics of grazed swards. In: SIMPÓSIO INTERNACIONAL DE ECOFISIOLOGIA DE PLANTAS FORRAGEIRAS E ECOLOGIA DO PASTEJO, 1., Curitiba, 1999. Anais... Curitiba: UFPR, 1999. p. 109-133.

MAZZANTI, A.; LEMAIRE, G.; GASTAL, F. The effect of nitrogen fertilization upon the herbage production of tall fescue swards continuously grazed with sheep. 1. Herbage growth dynamics. Grass and Forage

Science, Oxford, v. 49, p. 111-120, 1994. http://dx.doi.org/10.1111/j.1365-2494.1994.tb01983.x

NABINGER, C. Princípios da exploração intensiva de pastagens. In: SIMPÓSIO SOBRE MANEJO DA PASTAGEM, 13, 1996, Piracicaba. Anais... Piracicaba: FEALQ, 1996. p. 15-96.

OLIVEIRA, A. B.; PIRES, A. J. V.; MATOS NETO, U.; CARVALHO, G. G. P; VELOSO, C. M; SILVA, F. F. Morfogênese do capim-Tanzânia submetido a adubacões e intensidades de corte. Revista Brasileira de Zootecnia, Viçosa, v. 36, n. 4, p. 1006-1013, 2007.

PATÊS, N. M. S.; PIRES, A. J. V.; SILVA, C. C. F.; SANTOS, L. C.; CARVALHO, G. G. P.; FREIRE, M. A. L. Características morfogênicas e estruturais do capim-Tanzânia submetido a doses de fósforo e nitrogênio.

Revista Brasileira de Zootecnia, Viçosa, v. 36, n. 6, p. 1736-1741, 2007.

PETRY, L.; MESQUITA, E. E.; NERES, M. A.; ARAÚJO, J. S.; DREYER, M.; OLIVEIRA, E. de. Morfogênese de Panicum maximum cultivares Mombaça, Tanzânia e Millenium sob doses de nitrogênio. In: REUNIÃO ANUAL DA SOCIEDADE BRASILEIRA DE ZOOTECNIA, 42. Goiânia. Anais... Goiânia: SBZ, 2005.CD-ROM.

R DEVELOPMENT CORE TEAM (2009). R: A language and environment for statistical computing. R Foundation for Statistical Computing, Vienna, Austria. ISBN 3-900051-07-0, URL http://www.R-project.org

ROMA, C. F. C.; CECATO, U.; SOARES FILHO, C. V.; SANTOS, G. T. dos; RIBEIRO, O. L.; IWAMOTO, B. S. Morphogenetic and tillering dynamics in Tanzania grass fertilized and non fertilized with nitrogen according to season. Revista Brasileira de Zootecnia, Viçosa, v. 41, n. 3, p. 565-573, mar. 2012. 
SANTOS, P. M.; BALSALOBRE, M. A. A.; CORSI, M. Características morfogenéticas e taxa de acúmulo de forragem do capim-mombaça submetido a três intervalos de pastejo. Revista Brasileira de Zootecnia, Viçosa, v. 33, p. 843-851, jul./ago. 2004.

SANTOS, P. M. Controle do desenvolvimento das hastes no capim-tanzânia: um desafio. 2002. 98p. Tese (Doutorado em Agronomia) - Escola Superior de Agricultura Luiz de Queiroz, Piracicaba.

SILVEIRA, C. P.; MONTEIRO, F. A. Morfogênese e produção de biomassa do capim-Tanzânia adubado com nitrogênio e cálcio. Revista Brasileira de Zootecnia, Viçosa, v. 36, n. 2, p. 335-342, mar./abr. 2007.

VOLENEC, J. J.; NELSON, C. J. Responses of Tall fescue leaf meristems to N fertilization and harvest frequency. Crop Science, Madison, v. 23, p. 720-724, 1983.

http://dx.doi.org/10.2135/cropsci1983.0011183X002300040028x

WERNER, J. C.; COLOZZA, M. T.; MONTEIRO, F. A. Adubação de pastagens. In: SIMPÓSIO SOBRE MANEJO DE PASTAGENS, 18., 2001, Piracicaba. Anais... Piracicaba: FEALQ, 2001. p. 129-156.

WERNER, J. C.; PAULINO, V. T.; CANTARE LLA, H. Forrageiras. In: RAIJ, B. Van; CANTARE LLA, H.; QUAGGIO, J. A.; FURLANI, A. M. C. (Eds.). Recomendações de adubação e calagem para o Estado de São Paulo. Campinas: Instituto Agronômico, 1996. p. 263-273 (Boletim técnico, 100). 